\title{
Changes in biochemical and nutritional properties of bekang- um (fermented soybean) prepared by traditional method and customized incubator
}

\author{
K. Thanzami*, C. Lalremruati, Vanlalthlana, Andrew Lalthasanga, Phyobemo C. Tungoe, \\ Joseph L. Ralte, H. Lalhlenmawia \\ Department of Pharmacy, Regional Institute of Paramedical and Nursing Sciences, Zemabawk 796017, Mizoram, India
}

\begin{abstract}
Effect of controlled and uncontrolled fermentation temperature on the microbial load, biochemical changes and change in nutritive value of bekang-um was studied in an attempt to upgrade the traditional fermentation technology of soybean, Glycine max (L.) Merr. The sterile cooked beans were fermented using a low-cost wooden incubator developed previously, adjusted at a constant temperature $\left(35^{\circ} \mathrm{C}\right)$ and also under direct sunlight for 4 days following the traditional method. The microbial load, biochemical changes and changes in nutritive values of both the beans fermented were compared under controlled and uncontrolled temperature. The result showed that the viable cell counts, $\mathrm{pH}$, free amino acids, proteolytic activity and alpha amylase activity increased in both the fermenting conditions throughout the process while the reducing sugar increased in the first day and decreased gradually with fermentation in both conditions. There is also an increase in moisture, protein and calorific value, and a decrease in carbohydrate, fats and ash value in both conditions. Fermentation under controlled temperature gave the higher levels of alpha amylase and proteolytic activities, viable cell counts, $\mathrm{pH}$, free amino acids and nutritive value. These results suggested that fermentation proceeds at higher rate under controlled temperature using low-cost incubator could be utilized for the commercial production of bekang-um as the fermentation time could be reduced from three days to two days in addition to its simpler technology.
\end{abstract}

Keywords: Bekang-um, biochemical changes, fermentation, nutritive value, soybean, temperature.

\section{Introduction}

Bekang-um is an indigenous fermented product of soybean, popularly used as a food condiment among the local people of Mizoram in the northeastern region of India. It has a characteristic smell, flavor and stickiness. Flavorsome and sticky products of fermented dry seeds of soybean are popular inthe eastern parts of Nepal, Darjeeling hills, Sikkim, north- eastern regions of India, and southern parts of Bhutan. Some of the common ethnic fermented products of soybean of the Eastern Himalayas are kinema (Nepal, Darjeeling hills, Sikkim, and south Bhutan), tungrymbai (Meghalaya), aakhone (Nagaland), hawaijar (Manipur) and peruyaan (Arunachal Pradesh). ${ }^{1}$

Bekang-um is a traditional fermented food product prepared from the seeds of soybean, Glycine max (L.) Merr., by the indigenous Mizo 
people. It is a sticky food which serves as a cheap source of high protein food in local diet. It is consumed as it is, or made into curry with the addition of salt, green chillies, and tomatoes. It is commonly used as a side dish and often used as a food seasoning. ${ }^{2}$ In the traditional production of bekang-um, soybeans are cleaned, soaked overnight in tap water and cooked by boiling for few hours. The cooked beans are then placed in a traditional bamboo basket (kho) lined with hnahkiah (Callicarpa arborea) leaves, sprinkled clean wood ash over the beans, covered with clean hnahkiah leaves properly and left to ferment in the fireplace or under direct sunlight for 4 days.

There is very less information on the microbiological, biochemical and nutritional changes during the fermentation of bekang-um. Since its production has remained a traditional skill with very few data, there is variability in the preparation from one household to another resulting into products of variable characteristics and quality. Moreover, as fermentation proceeds under natural condition in the traditional method, there can be lots of variability in the taste and quality of the fermented products depending upon the seasonal and climatic changes. Hence, there is a need for optimization of the process conditions to improve and maintain the quality which would assure general acceptability of the product.

Bekang-um is traditionally produced on a smallscale basis in homes with low investment. Therefore, there is a struggle in upgrading the fermenting technology although it is a necessity to produce quality products. The modern commercial instruments are expensive and not affordable by the major producers of bekang-um as most of them are from economically backward household. In this study, a low-cost incubator made of wood and electric bulb was made to replicate the high cost incubator. Then, the microbiological and biochemical changes including extracellular enzyme activities and nutritive value during four days of fermentation of soybean under controlled temperature using lowcost incubator and uncontrolled temperature traditional method were determined and compared.

\section{Materials and Methods}

\section{Materials}

Plywood, aluminum sheet, wooden plank, nails, varnish, electric bulb and holder, thermometer, digital automatic timer, soybean seeds, autoclave, hnahkiah leaves, distilled water, tray, $\mathrm{pH}$ meter, maximum recovery diluent (MRD consisting of peptone and sodium chloride), petridish, bacteriological incubator, homogeniser, standard glucose, dinitrosalicylic acid reagent (DNS), UV-Vis spectrophotometer, ethanol, standard glycine, 0.05 $\mathrm{M}$ acetate buffer ( $\mathrm{pH} 4.8)$, ninhydrin reagent, $0.1 \mathrm{M}$ phosphate buffer (pH 6.0), vortex mixer, casein, $10 \%$ TCA, $0.05 \mathrm{M}$ phosphate buffer ( $\mathrm{pH} 7.0)$, starch, Whatman no 1, anthrone reagent, $2.5 \mathrm{~N} \mathrm{HCl}$, waterbath, solid sodium carbonate, centrifuge, crucible, hot air oven, dessicator, Soxhlet apparatus, micropipette, petroleum ether, Kjiehldahl apparatus, sodium sulphate, copper sulphate, conc. $\mathrm{H}_{2} \mathrm{SO}_{4}, 40 \%$ $\mathrm{NaOH}, 2$ \% boric acid, $0.1 \mathrm{M} \mathrm{HCl}$, universal indicator (methyl red + bromocresol green, muffle furnace, waterbath, analytical balance, colony counter, etc.

\section{Construction of low-cost incubator}

Firstly, wooden plank was collected and cut into appropriate sizes, i.e. 2 feet each and fixed together with hammer and nails to form a 2 feet square structure or foundation. Aluminum sheet was used to lineinside of the box and so that warm air can be circulated evenly inside the box. Three shelves were made using small wooden pieces inside the box for placement of the tray. 2 feet square of plywood which was cut earlier was taken and placed on each side of the outer part and fixed onto the wooden structure, leaving one side for the door. The door was made with a fine structure and thermocol was pasted on the edge of the inner side of the door which makes the box air tight. This help in maintaining the warm temperature inside the incubator and in the mean time, prevents the warm air from escaping and cold air from entering into the incubator. A small hole for insertion of bulb holder was made at the bottom corner of the incubator. The wire connecting the bulb and the holder was further connected to digital automatic timer which could be set to automatically switch off and on the electric bulb at different time intervals as per required. Incubator stand was made using the remaining wood and handle was fitted on both the upper side of the incubator.

After completion of the construction part, an incandescent halogen light bulb of 60 watt was fixed to the bulb holder and switched on. A thermometer was placed inside the incubator to check the increase in temperature. The time required for the temperature of the incubator to reach $35 \pm 1^{\circ} \mathrm{C}$ after switching on the bulb and the time taken by the incubator to fall below $35^{\circ} \mathrm{C}$ after the bulb was switched off was recorded and the automatic timer was set accordingly so that the temperature inside the incubator remains at $35 \pm 1{ }^{\circ} \mathrm{C}$ at all time.

\section{Preparation of bekang-um}

Soybean seeds were collected from the local market in Aizawl, Mizoram. $1 \mathrm{~kg}$ of soybean seeds was washed thoroughly with tap water and soaked overnight with sufficient amount of distilled water. It was autoclaved with water for one hour at $121^{\circ} \mathrm{C}$ at 15 psi to obtain a sterile cooked beans instead of the traditional method of boiling for few hours. It was 
then divided into two equal lots, to be fermented under controlled (C) and uncontrolled (U) temperature. The two lots were further distributed to four (4) trays $\left(C_{1}, C_{2}, C_{3}, C_{4}\right.$ and $\left.U_{1}, U_{2}, U_{3}, U_{4}\right)$, i.e. a total of eight (8) trays, each lined with clean hnahkiah leaves. After placing the cooked soybean on the hnahkiah-lined trays, clean firewood ash was sprinkled evenly on the top of the soybean seeds and the seeds were then covered properly with layers of hnahkiah leaves. The trays were subjected to two different fermenting conditions, i.e. four trays $C_{1}, C_{2}, C_{3}$ and $C_{4}$ were kept under controlled temperature while $U_{1}, U_{2}, U_{3}$ and $U_{4}$ were kept under uncontrolled temperature. Under controlled temperature, the trays containing soybean were placed in a low cost wooden incubator where an electric bulb was used as a heat source and the temperature was adjusted using automatic timer. The temperature was maintained at $35^{\circ} \mathrm{C}$ which is reported as an optimum temperature for soybean fermentation by Omafuvbe 3 , by controlling the off time at 2 hours consecutively which turned on automatically after 15 minutes from the off time during 4 days. Under uncontrolled temperature, the samples were placed under direct sunlight for 4 days and the fermenting temperature varies depending upon the weather and also the ime of the day/night. Each tray was removed every day for examination from the 2 sets of fermentation, $C_{1}$ and $\mathrm{U}_{1}$ on the first day, $\mathrm{C}_{2}$ and $\mathrm{U}_{2}$ on the second day and so on.

\section{Viable cell count}

Fermenting beans (5 $\mathrm{g}$ wet wt.) were homogenized with $45 \mathrm{ml}$ of sterile MRD. Further dilutions were made in sterile MRD and $1 \mathrm{ml}$ of appropriate serial dilutions was plated in duplicate in nutrient agar using pour plate technique. Inoculated plates were incubated at $30^{\circ} \mathrm{C}$ for 48 hours following which the colony was counted. ${ }^{3}$

\section{pH value determination}

Fermenting beans (4 $\mathrm{g}$ wet wt.) were blended with $16 \mathrm{ml}$ of distilled water. The $\mathrm{pH}$ of the slurry was measured with a $\mathrm{pH}$ meter. ${ }^{3}$

\section{Determination of sugar and free amino acids}

The soluble sugars and free amino acid content of the fermenting beans were extracted with $80 \%$ ethanol (v/v) following the method of Odibo et $a l^{4}$ The ethanolic extract was appropriately diluted for the various determinations.

\section{Estimation of reducing sugar}

To $1 \mathrm{ml}$ of sample and glucose standard solution in $0.05 \mathrm{M}$ acetate buffer $(\mathrm{pH} 4.8)$ with concentration ranging from $10-100 \mu \mathrm{g} / \mathrm{ml}, 1 \mathrm{ml}$ of $0.05 \mathrm{M}$ acetate buffer ( $\mathrm{pH}$ 4.8) was added and mixed. $3 \mathrm{ml}$ DNS reagent was added to all the test tubes and mixed well. The tubes were placed in a boiling water bath for 5 minutes. The tubes were cooled to room temperature and the absorbance was measured at $540 \mathrm{~nm}$ with UV- visible spectrophotometer. ${ }^{5}$

\section{Estimation of amino acids by ninhydrin}

$1 \mathrm{ml}$ of sample and standard amino acid (glycine) solution with concentration ranging from 10-100 $\mu \mathrm{g} /$ $\mathrm{ml}$, distilled water was added to make up the volume to $4 \mathrm{ml}$. $1 \mathrm{ml}$ of ninhydrin reagent was added to all the test tubes and mixed by vortexing the tubes. The test tubes were placed in boiling water bath for 15 minutes and cooled in cold water and $1 \mathrm{ml}$ of ethanol was added to each test tube and mixed well. The absorbance was then measured at $570 \mathrm{~nm}$ with UV-visible spectrophotometer. ${ }^{6}$

\section{Determination of proteinase activity}

The extracting buffer was $0.1 \mathrm{M}$ phosphate buffer ( $\mathrm{pH}$ 6.0) as described by Omafuvbe et al. ${ }^{7}$ The assay method used was that of Young and Wood. ${ }^{8} 5 \mathrm{ml}$ of the extract was added to $10 \mathrm{ml}$ of $2 \%$ solution of casein and incubated at $35^{\circ} \mathrm{C}$ for $30 \mathrm{~min}$. The reaction was terminated by adding $10 \mathrm{ml}$ of $10 \%$ trichloroacetic acid (TCA) solution. The mixture was filtered through Whatman no. I filter paper. The absorbance was measured at $275 \mathrm{~nm}$ with UV-visible spectrophotometer. The blank contained the same mixture but with the TCA added simultaneously with the enzyme extract. One unit of activity was defined as the amount of enzyme that produced an absorbance increase in 30 minutes under the experimental conditions.

\section{Determination of a-amylase activity}

The extracting buffer was $0.05 \mathrm{M}$ phosphate buffer ( $\mathrm{pH}$ 7.0) as described by Omafuvbe. ${ }^{9}$ The assay procedure described by Bernfeld ${ }^{10}$ was used. 2 $\mathrm{ml}$ of the extract was mixed with $1 \mathrm{ml}$ of $1 \%$ starch solution and incubated for 1 hour at $40^{\circ} \mathrm{C}$. The reaction was stopped by adding $3 \mathrm{ml}$ dinitrosalicylic acid reagent (DNS). The mixture was heated in a boiling water bath for $5 \mathrm{~min}$, cooled in cold water, and then diluted with $18 \mathrm{ml}$ water. The absorbance of the resultant solution was measured at $550 \mathrm{~nm}$, using UV- visible spectrophotometer. The blank was similarly treated except that the DNS was added before adding the starch solution. One unit of activity was defined as the amount of enzyme that produced an absorbance increase in 60 minutes under the assay conditions. 


\section{Determination of total carbohydrates}

$100 \mathrm{mg}$ of the sample was hydrolysed by keeping it in boiling water bath for 3 hours with $5 \mathrm{ml}$ of $2.5 \mathrm{~N}$ $\mathrm{HCl}$ and cooled to room temperature. It was then neutralised with solid sodium carbonate until the effervescence ceases and the volume as made up to $100 \mathrm{~mL}$ and centrifuged. The supernatant was collected and $1 \mathrm{ml}$ aliquot was taken for analysis. The standards were prepared by taking $0,0.2,0.4,0.6,0.8$ and $1 \mathrm{ml}$ of the working glucose standard $(0.1 \mathrm{mg} /$ $\mathrm{ml}$ ) and ' 0 ' served as blank. The volume was made upto $1 \mathrm{ml}$ in all the tubes including the sample tubes by adding distilled water. $4 \mathrm{ml}$ of anthrone reagent was then added and heated for 8 minutes in a boiling water bath. It was then cooled rapidly and the absorbance was measured at $630 \mathrm{~nm}$. A standard graph was drawn by plotting concentration of the standard on the $X$-axis versus absorbance on the $Y$ axis. From the graph, the amount of carbohydrate present in the sample tube was calculated. ${ }^{11}$

Amount of carbohydrate present in $100 \mathrm{mg}$ of

$$
\text { sample }=\frac{\text { Amount of glucose }(\mathrm{mg})}{\text { Volume of test sample }} \times 100
$$

\section{Total moisture content}

Moisture was determined by the AOAC method. ${ }^{12}$ $2 \mathrm{~g}$ of the fermented soybean sample was placed in reheated, re-weighed crucibles; each crucible with its sample was dried in oven at $105^{\circ} \mathrm{C}$ overnight. The crucible was transferred to desiccators, left to cool and weighed. The moisture content of the sample was calculated according to the following formula:

$$
\text { Moisture } \%=\frac{\text { Weight loss }}{\text { Weight of the sample }} \times 100
$$

\section{Total fat content}

Total fat was determined according to the AOAC method. ${ }^{12} 20 \mathrm{~g}$ of the sample was extracted with petroleum spirit for 8 hours in Soxhlet apparatus. The extract was dried, cooled and weighed. The fat content was calculated as:

$$
\text { Fat } \%=\frac{\text { Weight of extracted oil }}{\text { Weight of the sample }} \times 100
$$

\section{Protein content}

Nitrogen content was determined by the micro Kjeldahl technique following the method of the AOAC method. ${ }^{12} 0.2-0.3 \mathrm{~g}$ of the sample was weighed into a micro Kjeldahl flask with five grams of sodium sulphate and one gram of copper sulphate also added as catalyst mixture and $10 \mathrm{ml}$ of concentrated sulfuric acid was added. The solution was then heated in a digestion flask until the solution became green. The sample was placed into the distillation apparatus. $20 \mathrm{ml}$ of $40 \% \mathrm{NaOH}$ were added. The ammonia evolved was received in $10 \mathrm{ml}$ of $2 \%$ boric acid solution. The trapped ammonia was titrated against $0.1 \mathrm{M} \mathrm{HCl}$ using universal indicator (methyl red + bromocresol green).

$\%$ Nitrogen $=$

Volume of $\mathrm{HCl} \times$ Molarity of $\mathrm{HCl} \times 1.4007$

Weight of the sample

Protein $=\%$ Nitrogen $\times$ Power Factor $(6.25)$

\section{Ash content}

Total ash was determined according to the AOAC method (1984). ${ }^{12} 2 \mathrm{~g}$ of the sample was ignited at $500^{\circ} \mathrm{C}$ in a muffle furnace (overnight).

$$
\text { Ash } \%=\frac{\text { Weight of ash }}{\text { Weight of sample }} \times 100
$$

\section{Calorific value}

Calorific values were determined as described by Maynard $(1944)^{13}$ using the following formula:

$$
\begin{aligned}
& \text { Calorific Value }= \\
& \% \text { Carbohydrate } \times 4+\% \text { Fat } \times 9+\% \text { Protein } \times 4
\end{aligned}
$$

\section{Results}

The changes in viable cell counts and $\mathrm{pH}$ of fermented soybean under under controlled and uncontrolled temperature were measured during soybean fermentation and recorded in Table 1. The changes in free amino acids during soybean fermentation under controlled and uncontrolled temperature at different days of fermentation were determined and compared as shown in Figure 1. The free amino acids (mg glycine/g wet wt.) was 0.225 $\mathrm{mg}$ before fermentation and increases to $0.487 \mathrm{mg}$, $0.549 \mathrm{mg}, 0.584 \mathrm{mg}$ and $0.630 \mathrm{mg}$ under controlled temperature, and also increases to $0.478 \mathrm{mg}, 0.501$ $\mathrm{mg}, 0.579 \mathrm{mg}$ and $0.621 \mathrm{mg}$ under uncontrolled temperature at day 1, 2, 3 and 4 respectively.

The changes in proteolytic activity during soybean fermentation under controlled and uncontrolled temperature at different days of fermentation were measured and compared in Figure 2. Under controlled temperature, the proteolytic activity (unit/ml) was 2.89 on the first day and increases to $3.34,3.72$ and 4.20 on the second, third and fourth days respectively. Under uncontrolled temperature, the proteolytic activity (unit/ml) was 2.46 on the first day and increases to $3.19,3.62$ and 3.87 on the second, third and fourth days respectively. 


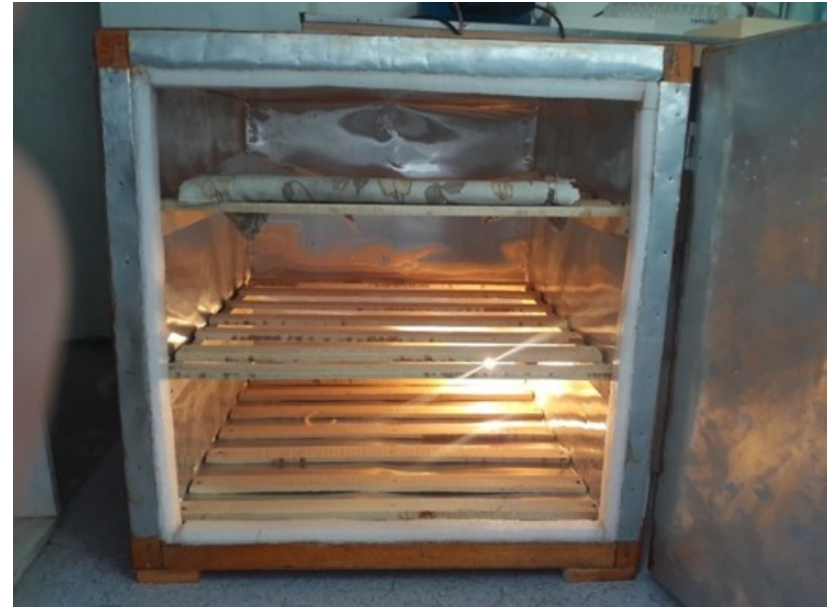

Figure 1 | Low-cost incubator developed for fermentation of soybean at constant temperature.

The changes in reducing sugar during soybean fermentationunder controlled and uncontrolled temperature were measured at different days of fermentation and compared as shown in Figure 3. The reducing sugar (mg glucose/g wet wt.) was $0.249 \mathrm{mg}$ before fermentation and decreases to 0.28 $\mathrm{mg}, 0.034 \mathrm{mg}, 0.029 \mathrm{mg}$ and $0.024 \mathrm{mg}$ under controlled temperature, and also decreases to 0.309 $\mathrm{mg}, 0.15 \mathrm{mg}, 0.141 \mathrm{mg}$ and $0.094 \mathrm{mg}$ under uncontrolled temperature at day 1, 2, 3 and 4 respectively.

The changes in $\alpha$-amylase activity during soybean fermentation under controlled and uncontrolled temperature at different days of fermentation were determined and compared in Figure 4. Under controlled temperature, the $\alpha$-amylase activity (unit/ $\mathrm{ml}$ ) was 9.15 on the first day and increases to 9.25 , 19.93 and 20.65 on the second, third and fourth days respectively. Under uncontrolled temperature, the $\alpha$ amylase activity (unit/ml) was 6.25 on the first day and increases to $6.75,18.29$, and 18.79 on the second, third and fourth days respectively. The nutritive value like carbohydrate, protein, moisture content, ash value, fats and calorific value of fermented soybean at different days of fermentation under the two different conditions were estimated and shown in Table 2.

\section{Discussion}

A low-cost incubator was developed using a plank of wood, plywood and aluminium sheet where incandescent halogen electric bulb was used as a heat source and the temperature was adjusted using automatic timer (Fig. 1). Using this timer, the temperature could be maintained at $35 \pm 1{ }^{\circ} \mathrm{C}$ by setting the timer to switch off after 2 hours of switching on the bulb and to turn on after 15 minutes of switching off. The incubator developed cost approximately INR 2,000 only while commercially available incubator of the same size would cost around INR 10,000 and above depending upon the manufacturer.

The viable cell count of the fermented soybean in both controlled and uncontrolled temperatures increased rapidly in the first day of fermentation and then slowed down in the latter stages of fermentation (Table 1). This trend has been reported by several authors. ${ }^{7,14,9}$ The increase in cell count was significantly higher in controlled temperature from the onset to the end of fermentation. The higher increase in viable cell counts in controlled temperature may indicate that a constant

Table 1 | Changes in viable cell counts and pH during soybean fermentation under controlled and uncontrolled temperature.

\begin{tabular}{cccccccccc}
\hline & \multicolumn{4}{c}{ Controlled temperature } & \multicolumn{3}{c}{ Uncontrolled temperature } \\
& Day 0 & Day 1 & Day 2 & Day 3 & Day 4 & Day 1 & Day 2 & Day 3 & Day 4 \\
\hline Viable cell count & 5 & 92 & 122 & 141 & 166 & 62 & 97 & 109 & 128 \\
\hline pH & 5.25 & 5.60 & 6.19 & 7.39 & 8.47 & 5.53 & 5.83 & 6.87 & 8.34 \\
\hline
\end{tabular}

Table 2 | Changes in nutritive value during soybean fermentation under two different conditions.

\begin{tabular}{lccccccccc}
\hline $\begin{array}{l}\text { Nutritional } \\
\text { Composition }\end{array}$ & \multicolumn{3}{c}{ Controlled temperature } & \multicolumn{4}{c}{ Uncontrolled temperature } \\
\hline Darbohydrate (mg/100 mg) & 3.48 & Day 1 & Day 2 & Day 3 & Day 4 & Day 1 & Day 2 & Day 3 & Day 4 \\
\hline Protein (\%) & 19.76 & 22.01 & 2.14 & 1.62 & 0.74 & 4.66 & 2.64 & 1.90 & 0.96 \\
\hline Moisture (\%) & 20 & 21.5 & 22.5 & 29.16 & 31.31 & 21.13 & 23.80 & 27.14 & 30.55 \\
\hline Ash (\%) & 1.65 & 1.35 & 1.20 & 1.05 & 1 & 1.30 & 1.15 & 1.10 & 1 \\
\hline Fats (\%) & 0.9 & 0.8 & 0.6 & 0.55 & 0.3 & 0.85 & 0.65 & 0.5 & 0.35 \\
\hline Calorific value (Kcal/100 g) & 101.0 & 112.8 & 114.9 & 128.07 & 130.9 & 110.8 & 111.6 & 120.6 & 129.1 \\
\hline
\end{tabular}




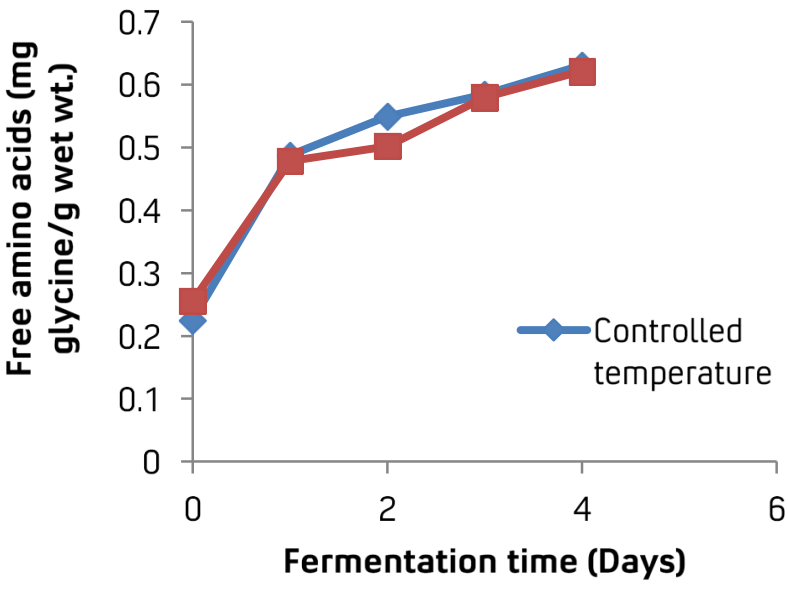

Figure 2 | Changes in free amino acids during soybean fermentation under controlled and uncontrolled temperature.

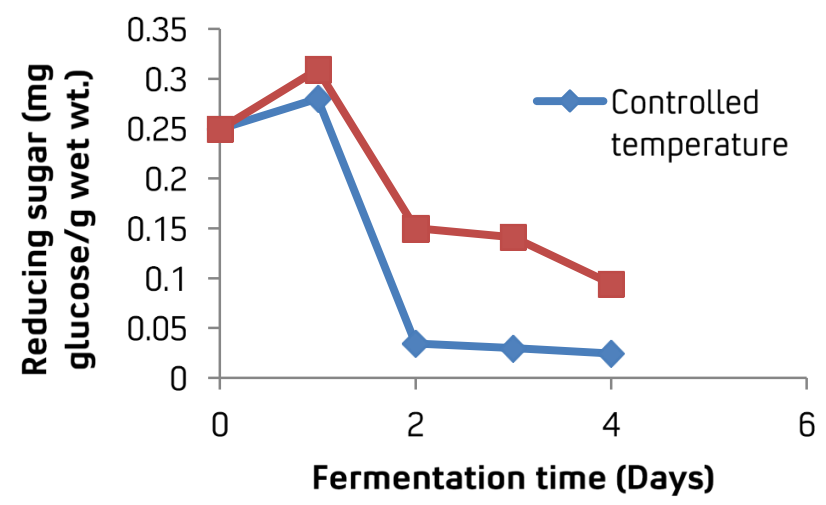

Figure 4 | Changes in reducing sugar during soybean fermentation under controlled and uncontrolled

temperature creates a favorable condition for the growth of fermenting microorganisms.

The effect of fermentation on $\mathrm{pH}$ change was observed under controlled and uncontrolled temperature and ranges from 5.25 to 8.47 (Table 1). The $\mathrm{pH}$ was significantly higher in controlled temperature in the first 3 days of fermentation and thereafter the values became steady at the end of fermentation. The differences may be due to the temperature differences during fermentation. The steady $\mathrm{pH}$ at the end of fermentation may indicate the end point of fermentation where the fermenting beans are no more fit for consumption. Increase in $\mathrm{pH}$ during fermentation of protein-rich beans have also been reported by several authors., ${ }^{7,15}$ This has been attributed to proteolytic activities and the release of ammonia following the utilization of amino acids by microorganisms involved in the fermentation. ${ }^{16}$ The release of ammonia or other basic end products have been reported to be

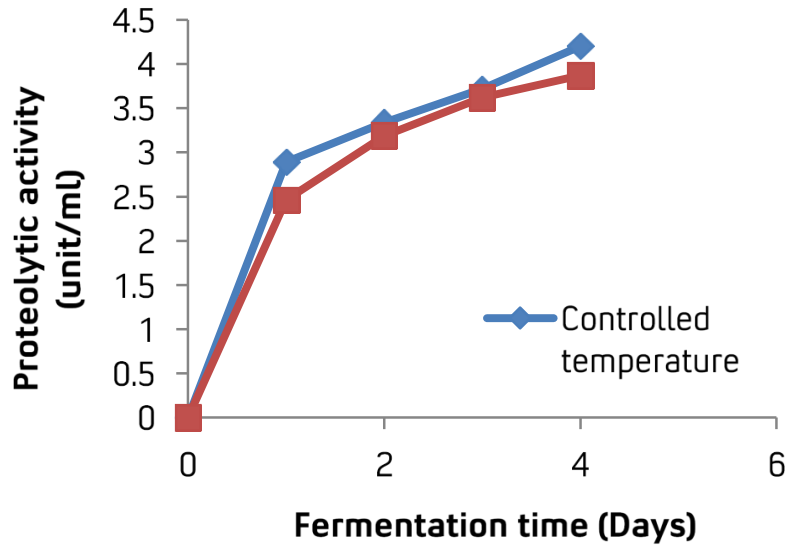

Figure 3 | Changes in proteolytic activity during soybean fermentation under controlled and uncontrolled temperature.

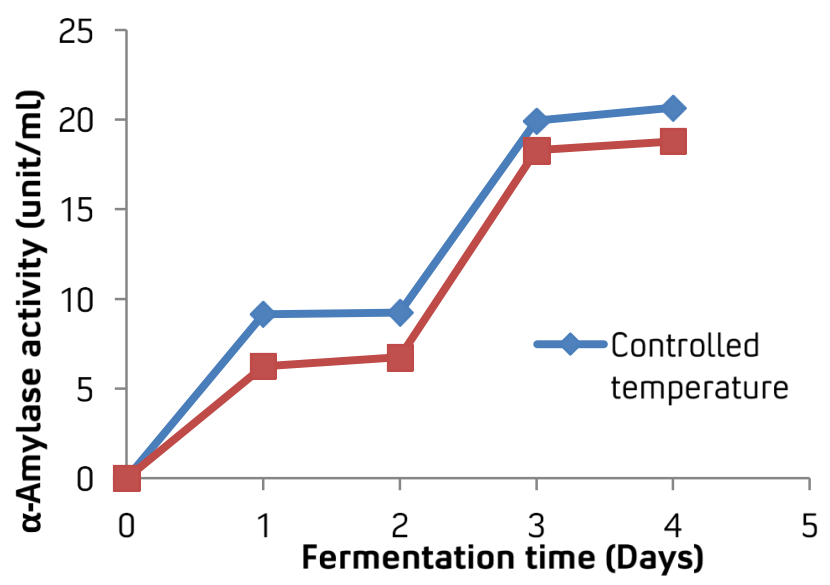

Figure 5 | Changes in $\alpha$-amylase activity during soybean fermentation under controlled and uncontrolled temperature.

common features in the fermentation of vegetable proteins. $^{17}$

The total free amino acids and proteolytic activity increased rapidly in the first day and increased gradually in the later stages (2-4 days) of fermentation in both controlled and uncontrolled temperature (Fig. $2 \& 3$ ). The rapid increase in total free amino acids in the early stages of fermentation indicates a rapid protein hydrolysis which corresponds to the increased proteolytic activity of the fermenting organisms. This trend in the fermenting beans has been reported to indicate a two 'stage process'. The first stage is linked to the growth and protease production while the second stage of less activity is linked to product ripening. ${ }^{18}$ The total free amino acids and proteolytic activity was higher in controlled temperature.

The reducing sugar increased in the first day and decreased gradually with fermentation in both controlled and uncontrolled temperature (Fig. 4) 
while $\alpha$-amylase activity in the fermenting seeds increased gradually (Fig. 5). $\alpha$-Amylase may have been responsible for the increased level of reducing sugar in the fermenting seeds in the early stage of fermentation. ${ }^{7}$ The utilization of the soluble sugars by the increasing population of fermenting microorganisms may have been responsible for the significant drop in the reducing sugar levels. ${ }^{9}$ Higher level of decrease of reducing sugar in fermenting soybean under controlled temperature may presumably be due to the higher increase in microbial population.

Nutritive value analysis with fermentation in both controlled and uncontrolled temperature was done. There is an increase in moisture, protein, carbohydrates and calorific value, and a decrease in fats and ash value with fermentation in both the temperature conditions. Fermentation under controlled temperature gave the higher levels of moisture, protein, carbohydrates and calorific value. The increase in moisture content with fermentation may be due to the moist solid nature of the fermentation and the hydrolytic property of the fermenting substrate by the implicated microorganisms. ${ }^{8}$ Protein levels increased significantly in the fermented soybeans, which can be attributed to an increase in microbial mass during fermentation, causing extensive hydrolysis of protein molecules to amino acids and other simple peptides. ${ }^{19}$ The increase could also be as a result of the enzymatic hydrolysis of some inhibitors during fermentation. ${ }^{20}$ The decrease in carbohydrate content with increasing fermentation time could be due to theactivities of the fermenting microorganisms which utilized and transformed them into energy for growth and other cellular activities. ${ }^{21}$ Fat levels showed an insignificant decrease with increasing fermentation time and values range from 0.3 to 0.9 . The decrease in fat might be a result of the fermenting microorganisms using fats from soybeans as a source of energy. During the fermentation, the microorganisms synthesize lipase enzyme that will hydrolizethe triacylglycerol into free fatty acids. ${ }^{22}$ The decrease in ash content may be due to leaching of soluble inorganic salts into the soaking water during processing ${ }^{23}$ or the fermenting microorganisms might have used it for metabolic activites. $^{24}$

\section{Conclusion}

Fermentation was shown to have varying positive effects on biochemical and nutritional properties of bekang-um under both controlled and uncontrolled temperature. The results of this study show that fermentation under controlled temperature using low-cost incubator improves the biochemical and nutritional properties of bekang-um when compared with that fermented under uncontrolled temperature. Controlled temperature created an optimum environment for the growth of fermenting microorganisms, resulting in increased population, and enhanced proteolytic activity and increased free amino acids which are considered to be important flavor -enhancing compounds in many fermented foods. This study has also proved fermentation under controlled temperature to be a useful tool that can be used to improve the nutritional quality of bekang-um as well as decrease fermentation time, which will increase the utilization of bekang-um as health food and enhance its production. It was observed that at $\mathrm{pH} 6.0$ to 7.5 , bekang-um had the best flavor and optimum for consumption which was achieved from the second day of incubation using the low-cost incubator till the third day. However, with traditional method, it was only on the third day that the fermentation product reaches the optimal $\mathrm{pH}$ for consumption while on the fourth day, the $\mathrm{pH}$ of the product reached above $\mathrm{pH}$ 8.0. At this $\mathrm{pH}$, bekang-um started giving out an ammonical smell which was too intense with adverse flavor and we concluded that bekang-um was over-fermented that it was no longer fit for consumption. Further work can be done on ways to improve the fermentation processes for soybeans which might increase its quality and acceptability.

\section{Acknowledgement}

The authors gratefully acknowledge the financial grant from Department of Biotechnology, Ministry of Science and Technology, Govt of India through Institutional Level Biotech Hub (IBThub), RIPANS and facilities provided by Director, RIPANS.

\section{Conflict of interest}

None declared.

\section{References}

1. Singh, T.A., Devi, K.R., Ahmed, G. \& Jeyram, K. (2014). Microbial and endogenous origin of fibrinolytic activity in traditional fermented foods of Northeast India. Food Research International, 55, 356-362. https://doi:10.1016/ j.foodres.2013.11.028

2. Tamang, J.P. (2015). Naturally fermented ethnic soybean foods of India. Journal of Ethnic Foods, 2, 817. https://doi:10.1016/j.jef.2015.02,003

3. Omafuvbe, B.O. (2008). Effect of temperature on biochemical changes induced by Bacillus subtilis (SDA3) during starter culture fermentation of soybean into condiment (Soy-Daddawa). American Journal of Food Technology, 3, 33-41. https:// doi:10.3923/ajft.2008.33.41

4. Odibo, F.J.C., Nwabunnia, E. \& Osuigwe, D.I. 
(1990). Biochemical changes during fermentation of Telfairia seeds for ogiri production. World Journal of Microbiology and Biotechnology, 6, 425-427. https://doi.org/10.1007/BF01202127

5. Miller, G.L. (1959). Use of dinitrosalicylic acid (DNS) for determination of reducing sugars. AnalyticalChemistry, 31, 426-428. https:// doi.org/10.1021/ac60147a030

6. Yemm, E.W., Cocking, E.C. \& Ricketts, R.E. (1955). The determination of amino-acids with ninhydrin. Analyst, 80, 209-214. https://doi:10.1039/ an9558000209

7. Omafuvbe, B.O., Shonukan, O.O. \& Abiose, S.H. (2000). Microbiological and biochemical changes in the traditional fermentation of soybean for soydaddawa - Nigeria food condiments. Food Microbiology, 17, 469-474. https://doi.org/10.1006/ fmic.1999.0332

8. Yong, F.M. \& Wood, B.J.B. (1977). Biochemical changes in experimental soy sauce Kofi. International Journal of Food Science \& Technology, 12, 163-175. https://doi.org/10.1111/j.1365-26211077.tb00096.x

9. Omafuvbe, B.O. (2006). Effect of salt on the fermentation of soybean (Glycine max) into daddawa using Bacillus subtilis as starter culture. African Journal of Biotechnology, 5, 1001-1005. https://doi.org/10.5897/AJB06.169

10. Bernfeld, P. (1955). Amylases and Proteinases. In: Methods in Enzymology (S.P. Colowicz \& N.O. Kaplan, eds), Academic Press, New York, United States, pp. 149-58. http://dx.doi.org/10.1016/00766879(55)01021-5

11. Hedge, J.E. \& Hofreiter, B.T. (1962). In: Carbohydrate Chemistry (R.L. Whistler \& J.N. Miller, eds), Academic Press, New York, United States, p. 420 .

12. AOAC (Association of Analytical Chemists) (1984). Standard Official Methods of Analysis of the Association of Analytical Chemists (S.W. Williams ed), Washington DC, pp. 5-9.

13. Maynard, L.A. (1944). The Atwater system of calculating the caloric value of diets. Journal of Nutrition, 28, 443-452. https://doi.org/10.1093/ jn/28.6.443

14. Amin, A.M., Jaafar, Z. \& Khim, N.L. (2004). The effect of salt on tempoyak fermentation and sensory evaluation. Journal of Biological Sciences, 4, 650-653. https://doi: 10.3923/jbs.2004.650.653

15. Babalola, R.O. \& Giwa, O.E. (2012). Effect of fermentation on nutritional and anti-nutritional properties of fermenting soybeans and the antagonistic effect of the fermenting organism on selected pathogens. International Research Journal of Microbiology, 3, 333-338.

16. Sarkar, P.K., Cook, P.E. \& Owens, J.D. (1993). Bacillus fermentation of soybeans. World Journal of Microbiology and Biotechnology, 9, 295-299. https:// doi.org/10.1007/BF00383066

17. Hasseltine, C.W. (1965). A millennium of fungi, food and fermentation. Mycologia, 57, 149-197. https://doi:10.1080/00275514.1965.12018201

18. Omafuvbe, B.O., Abiose, S.H. \& Shonukan, O.O. (2002). Fermentation of soybean (Glycine max) for soy-daddawa production by starter cultures of Bacillus. Food Microbiology, 19, 561-566. https:// doi.org/10.1006/fmic.2002.0513

19. Igbabul, B.D., Amove, J. \& Twadue, I. (2014). Effect of fermentation on the proximate composition, anti-nutritional factors and properties of cocoyam (Colocasia esculenta) flour. African Journal of Food Science and Technology, 5, 67 - 74. https:// doi.org/10.14303/ajfst.2014.016

20. Achi, O. (2005). Traditional fermented protein condiments in Nigeria. African Journal of Biotechnology, 4, 1612--1621.

21. Obadina, A.O., Akinola, O.J., Shittu, T.A. \& Bakare, H.A. (2013). Effect of natural fermentation on the chemical and nutritional composition of fermented soymilk Nono. Nigerian Food Journal, 31, 91-97. https://doi.org/10.1016/S0189-7241(15)30081 $-3$

22. Damanik, R.N.S., Pratiwi, D.Y.W., Widyastuti, N., Rustanti, N., Anjani, G. \& Afifah, D. N. (2018). Nutritional Composition changes during tempeh gembus processing. In: Earth and Environmental Science (IOP Conference Series). https:// doi:10.1088/1755-1315/116/1/012026

23. Osman, M.A. (2007). Effect of different processing methods on nutrient composition, anti-nutritional factors and in vitro protein digestibility of Dolichos lablab bean (Lablab purpuresus (L) Sweet). Pakistan Jornal of Nutrition, 6, 299-303. https://doi:10.3923/ pjn.2007.299.303

24. Beebe, S., Gonzalez, A.V. \& Rengifo, J. (2000). Research on trace elements in the common beans. Food and Nutrition Bulletin, 2, 1387-391. https:// doi.org/10.1177\%2F156482650002100408 